In: ISMÉRIO, Clarisse (Org.). Patrimônio Cultural: simbolismos, intertextualidades e polifonias [livro eletrônico]. São Paulo: Vecher, 2021. Disponível em: <https://doi.org/10.47585/9786599324215>.

\title{
A Associação Rural de Bagé (1939): patrimônio da arquitetura moderna bajeense
}

\author{
Magali Nocchi Collares Gonçalves ${ }^{1}$
}

doi.org/10.47585/9786599324215.4

O trabalho refere-se a um estudo analítico dos Pórtico de Acesso, Sede Social e Tribunas da Associação Rural de Bagé-RS, implantados no Parque Visconde Ribeiro de Magalhães, projeto do engenheiro porto-alegrense Carlos Machado Moreira, com base na dissertação de mestrado da autora "Arquitetura Bajeense - o delinear da modernidade: 1930-1970". Moreira, desenvolvendo sua obra em uma gama diversa de estéticas, o que era comum à época - década de 1940, projeta os exemplares como manifestações do estilo protomoderno, com elementos do art déco, estratégias compositivas que transferem às mesmas um caráter apropriado. Os prédios, condicionados à preservação plena dos seus elementos construídos - interna e externamente, alinham- se temporalmente às estéticas praticadas no Rio Grande do Sul e estão incluídos no conjunto de exemplares inventariados pelos Instituto do Patrimônio Histórico e Artístico Nacional - IPHAN e pelo Instituto do Patrimônio Histórico e Artístico do Estado - IPHAE como patrimônio histórico, cultural e arquitetônico bajeense.

Palavras-chave: Carlos Moreira; Protomoderno; Patrimônio; Composição; Caráter.

1 Doutora em Teoria História e Crítica da Arquitetura pela UFRGS. Professora do Curso de Arquitetura e Urbanismo no Centro Universitário da Região da Campanha - Urcamp, http://lattes.cnpq.br/0203419426444629, e-mail: magaligoncalves@urcamp.edu.br. 


\section{Introdução}

A agropecuária tem sido, através dos tempos, a atividade comercial e industrial principal da cidade de Bagé, localizada na extremidade audoeste do Rio Grande do Sul.

A Associação Rural de Bagé, fundada em 1904, abrigava suas intensas atividades comerciais, políticas, sociais e festivas com prédios e pavilhões em madeira, em gleba doada por Visconde Ribeiro de Magalhães. Localizada em distância igualitária entre o centro da cidade (na direção Norte) e as antigas Charqueadas (em sua direção Sudeste), com seu lado maior desenvolvendo-se ao longo de uma alameda de eucaliptos, hoje seculares, passa gradualmente através dos tempos a figura de uma ilha envolta de uma zona suburbana com uma ocupação crescente.

Nos anos 1940, face às necessidades da associação, em função do crescimento da cidade e da atividade agropastoril, implanta-se o Parque Visconde Ribeiro de Magalhães, ampliando a área aberta existente, e reconfigura-se a Associação Rural de Bagé, com nova Sede Social e Tribunas, bem como pavilhões, conforme um plano diretor interno, com previsões de procedimento para suas futuras necessidades.

Contrata-se o engenheiro Carlos Machado Moreira para o planejamento da organização espacial dos prédios principais e de apoio e criação de vias internas de acesso e circulação, reservatórios e bacias.

O Pórtico de Acesso, Sede Social e Tribunas, que segundo as solicitações do contratante deveriam obedecer a um padrão de qualidade na demonstração da importância da associação, são objetos que centralizam as intenções gerais do planejamento do parque rural e que são objetos desse estudo.

\section{Composição e Caráter na arquitetura de Carlos Moreira}

Conforme Mahfuz (1995, p. 23) “a paixão intuitiva se une ao espírito intelectual quando um objeto arquitetônico é mais do que um agregado de partes”. Acrescentando-se convicção decisória, repertório e técnica, delineia-se uma caracterização do profissional Carlos Moreira. Traduz-se o seu conhecimento, tecnologia, clareza, precisão e assimilação de referenciais teóricos a partir de sua formação na Escola de Engenharia de Porto Alegre, onde se diploma no final dos anos 1920.

A habilidade em desenvolver um projeto em simetria axial, sem prejuízos para a funcionalidade, não se resume a uma atitude cautelosa de juntar partes. Parece que o autor se utiliza do enquadramento de suas propostas em um Método Tipológico, que, segundo Mahfuz, consiste na utilização de tipos como base para geração da forma arquitetônica, "através do qual se gera um novo artefato arquitetônico por meio de uma analogia estrutural traçada com um outro artefato arquitetônico existente." (MAHFUZ, 1995, p. 80). 
A Sede Social, que tem no seu bojo o "Jockey Clube de Bagé", situa-se, por características programáticas, em situação compositiva que usa elementos a priori: dentro do método tipológico, segundo Mahfuz (1995, p. 80), ou do método ou projeto icônico para Geoffrey Broadbent (1976, p. 394), os quais se assemelham pelo uso de analogia, o primeiro, e de ícones, o último.

Os prédios antigos utilizados desde a fundação, em madeira, são removidos (Figura 1). Assim, o autor lança as novas instalações em terreno plano, com uma leve depressão na sua extremidade sudoeste, livre de construções, com trechos em pasto nativo e concentrações esparsas de árvores de grande porte.

\section{Figura 1 - Pavilhões de madeira anteriores às construções atuais.}

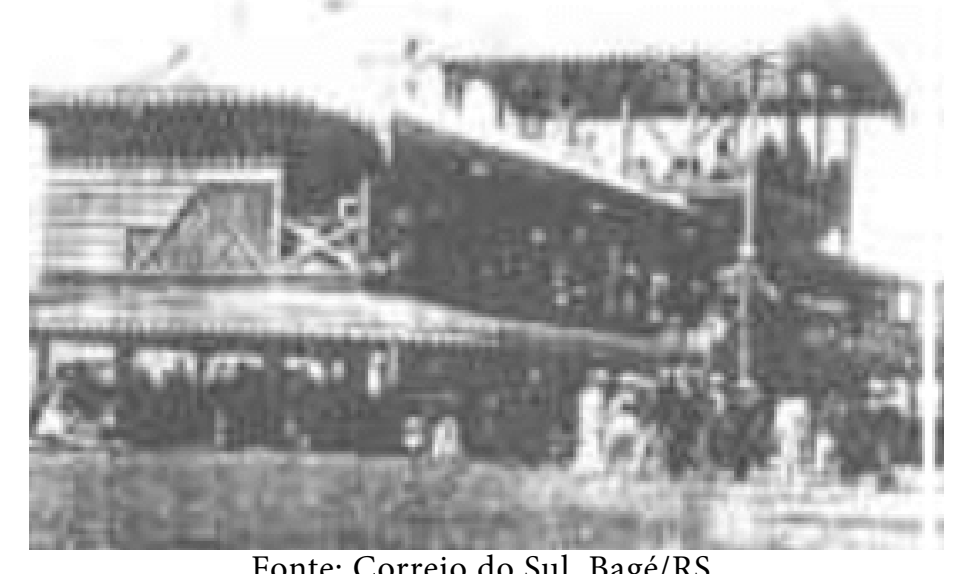

Fonte: Correio do Sul, Bagé/RS.

Em face de todas estas diversidades, comuns à época, numa tentativa de síntese metodológica do autor dos projetos observa-se: uso deliberado de geometria clara dentro dos princípios acadêmicos de simetria e axialidade; uso de vinculações tipológicas em sua metodologia de projeto, dentro de um repertório próprio; flexibilidade em situar sua obra dentro de uma linha ou corrente estilística, através do uso adequado de elementos de arquitetura; capacidade de criar um produto coerente em sua totalidade, se observar todos os parâmetros habituais; composição por elementos organizados conforme um tipo predeterminado e adição de um caráter apropriado através de elementos de arquitetura dentro de um ideário temporal.

\section{Projeto e análise}

Pela análise da implantação, presume- se que o programa de necessidades solicita: acesso principal através de um pórtico com bilheterias; Salão de Festas; acessos secundário para animais e abastecimento; uma área de grandes proporções, reservada para a pista do hipódromo; pavilhões de ovinos, bovinos e equinos; mangueiras; bacia de reserva de água e reservatório elevado; e outros pavilhões. A primeira decisão projetual é a de acomodação criteriosa da pista do hipódromo, um retângulo com os cantos arredondados, junto à 
extremidade maior do terreno em duplo trapézio (Figura 2).

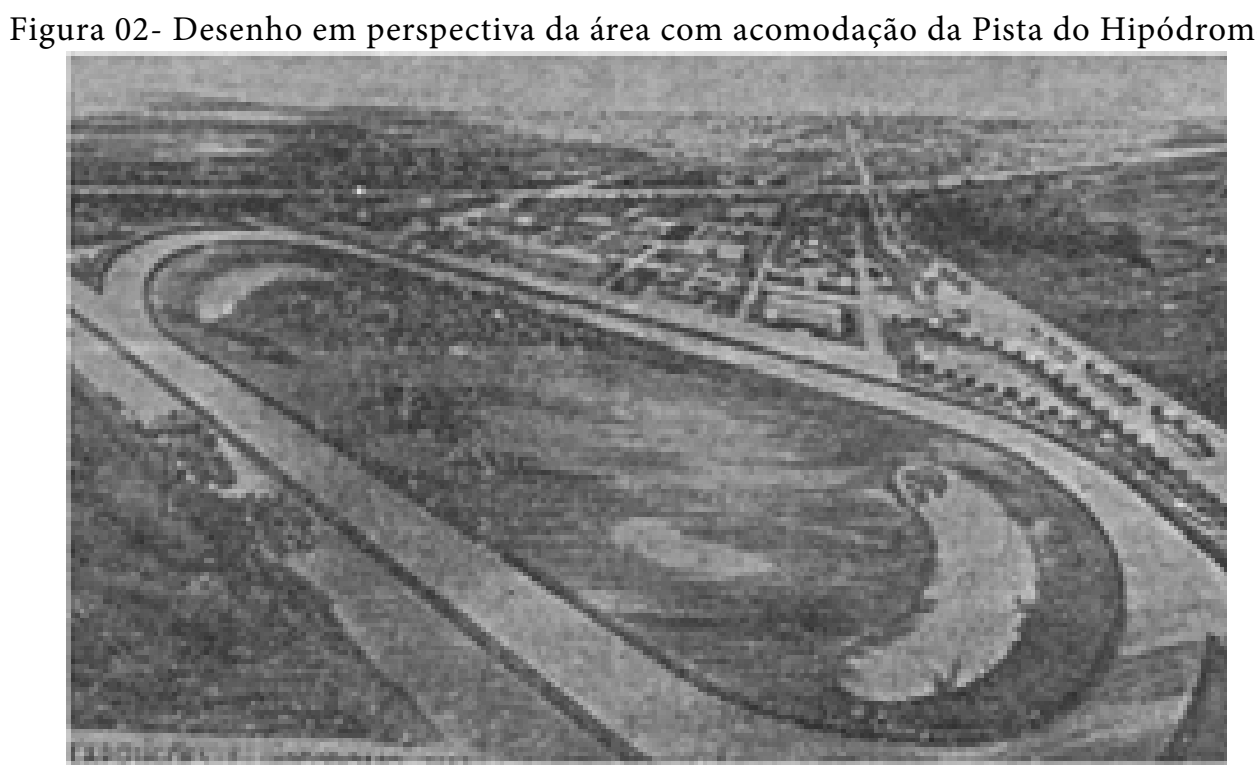

Fonte: Correio do Povo, 10 out. 1940.

Com a reserva da extremidade menor do trapézio para os pavilhões e mangueiras, abre-se uma faixa longitudinal, onde fixa-se um eixo central de acesso, a partir do Pórtico, chegando até a Sede Social e Tribunas, de onde se distribuem as atividades funcionais em ambas as laterais. O encaminhamento principal até o parque, desde o centro da cidade, e acesso do público dá-se através da Avenida Visconde Ribeiro de Magalhães, ficando as demais vias circundantes à área de acessos secundários de serviço.

Os prédios, de formas retangulares, implantam-se a partir do acesso com seus lados maiores paralelos à dimensão do lado maior do retângulo do hipódromo, gerando faces NO, SE, NE e SO, mais eficientes no caso de composições simétricas, sem distinção das aberturas nas faces opostas, como é o caso da Sede Social.

A imagem visual do parque é a de uma cidade rural, pela ortogonalidade dos encaminhamentos e um zoneamento e traçado viário hierárquico e eficiente. As compartimentações dos espaços abertos não acontecem ao acaso. Do espaço mais geral, público por excelência, do eixo central, ramificam-se ortogonalmente a funções específicas.

O eixo monumental (Figura 3) é atípico. Parece que o autor lança uma via de contemplação no sentido paralelo ao movimento, desconsiderando a perspectiva estática de um eixo que se direciona para um ponto focal extremo.

A estratégia de localização dos prédios é de distribuição ao longo do eixo, com um único pavilhão colocando-se no fechamento deste, mas que não se configura como ponto focal de importância para a composição. Esta interpretação reforça-se pelo lançamento de uma linha formada pelo Salão de Festas, Tribunas e Bacia, em ponto intermediário deste eixo, que determina um nó contemplativo e transversal, causando uma mudança de interesse visual. 


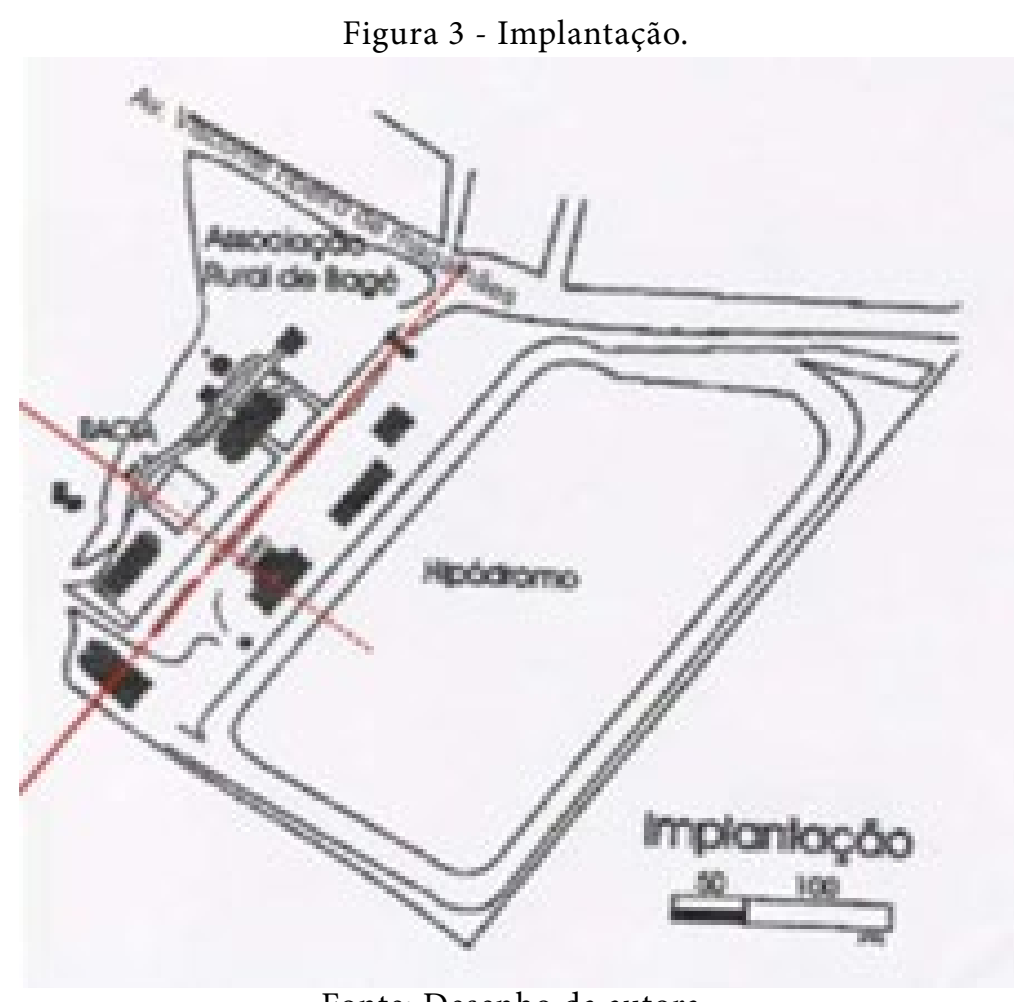

Fonte: Desenho da autora.

A implantação do Salão de Festas, descentrado ou lateral ao eixo, apesar de contraditória à primeira vista, ao considerar-se exemplos preexistentes axiais, é o que acrescenta conteúdo para o conjunto de Moreira, pelo gesto projetual incomum.

A obrigatoriedade funcional da concentração do Salão de Festas junto às Tribunas e Hipódromo, a colagem lançada pela necessidade de um contraventamento estrutural da plataforma através do volume da Sede Social, historicamente usada em clubes de jockey, aliadas à geometria do terreno, são definidoras desta atipicidade na implantação.

\section{O Pórtico de Acesso}

Dois volumes cilíndricos, com esquadrias para bilheterias distribuídas no contorno, e um pequeno prisma de base quadrada entre estes, com função de apoio central, demarcam a entrada e saída de veículos e público, encimados por uma laje plana, com letreiro identificativo ao longo de sua face frontal, e que é transpassada pelo prisma central formando uma torre com mastro.

O prolongamento do canteiro central da via principal para o lado externo do pórtico sugere uma contemplação em movimento do pórtico e uma vinculação mais próxima em relação a conjunto, refletindo mais uma situação de passagem, de convite, do que limite ou barreira. 
Figura 4 - Pórtico de Acesso. Planta baixa, vistas principal e lateral.

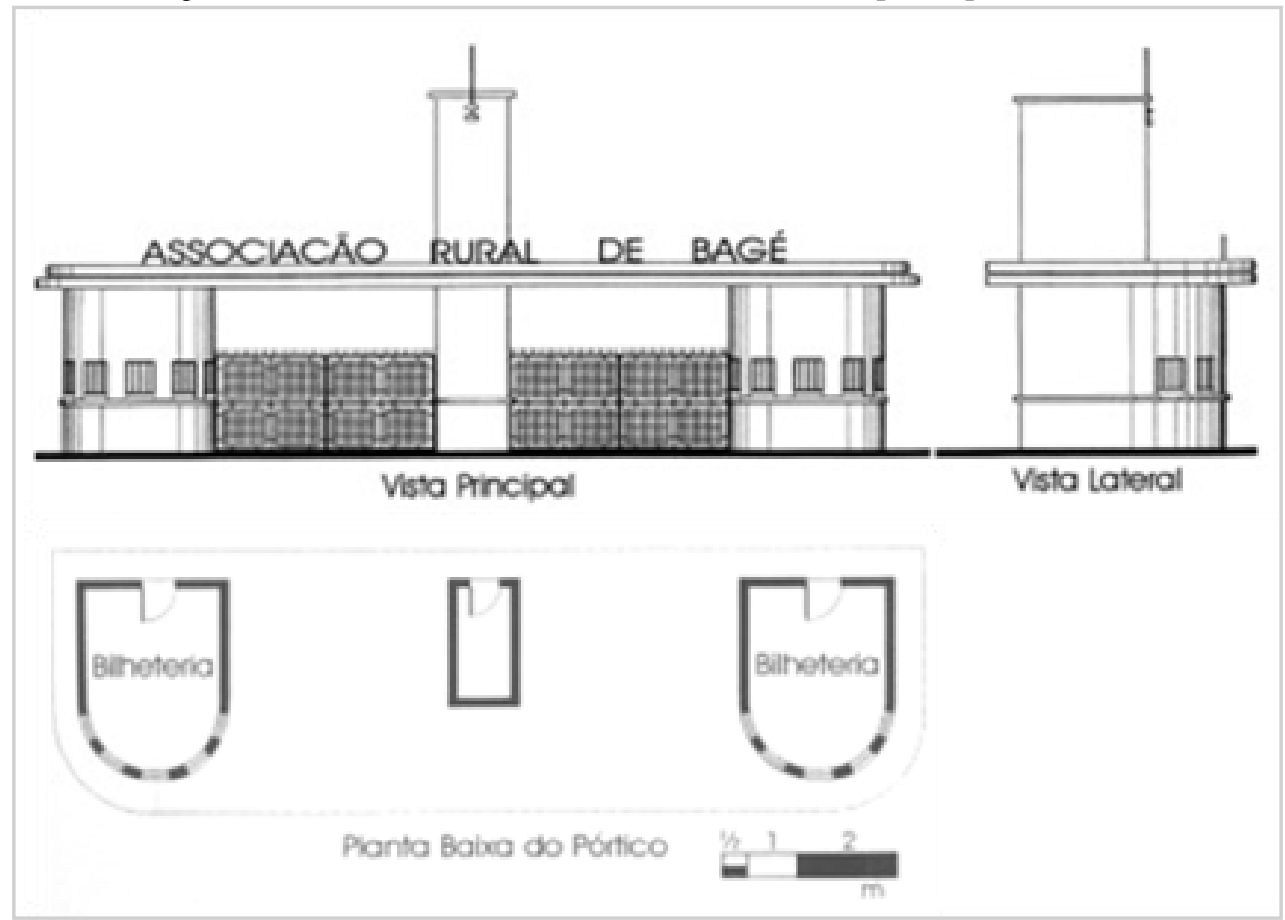

Fonte: Desenhos da autora.

Figura 5 - Pórticos da Exposição do Centenário da Revolução Farroupilha (E) e da Associação Rural de Bagé (D).
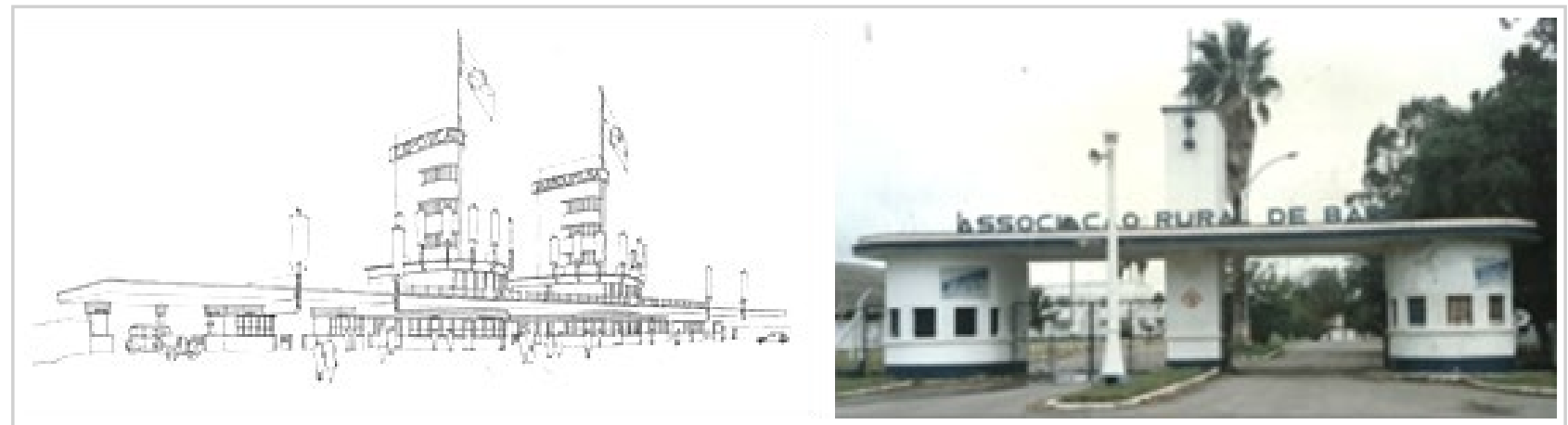

Fontes: ESKINAZI (1995) (E) e autora (D).

A volumetria é purista, com o uso de cilindros com modenaturas suaves, janelas equilibradamente distribuídas, como buracos na massa branca e marquise demarcando horizontalidade e transpassada por um elemento vertical.

A criação com elementos de composição cilíndricos, como bilheterias e torre, letreiros superiores, entre outros, remete a composição como referência ao pórtico monumental da Exposição Farroupilha, de 1935, do alemão Franz Filsinger (Figura 5).

\section{A Sede Social e Tribunas}

Numa descrição endógena, a planta desenvolve-se a partir de um átrio central coberto em pé-direito duplo, com subfunções sobrepostas e circundantes, nos dois pavimentos, conectadas a partir de duas escadas laterais, que participam esteticamente da composição. 
Em descrição axial, divide-se o perímetro em quatro momentos, o que é visualizado claramente nas plantas baixas, corte e elevações do exemplar (Figura 6).

O acesso principal centralizado é o primeiro, através de escadarias axiais para o público e rampas bilaterais para veículos, ambas fazendo a acomodação do prédio com o nível do parque, demarcado por uma marquise plana e levemente curvada. Esta cobertura longitudinal, apoiada em pilares cilíndricos, agrega-se às esquadrias e porta principal de acesso pela cuidadosa definição idêntica dos entre vãos de ambos. O foyer retangular alongado, com sanitários nas extremidades e painel em mármore - anteparo frontal ao acesso que dialoga com as aberturas da fachada - conduz a dois acessos laterais ao salão. Este volume coincide com o terraço no pavimento superior, o qual descreve frontalmente a mesma curva delineada na marquise, reforçando a demarcação de acesso.

Figura 6 - Sede Social e tribunas. Plantas baixas, cortes e vistas frontal e lateral.

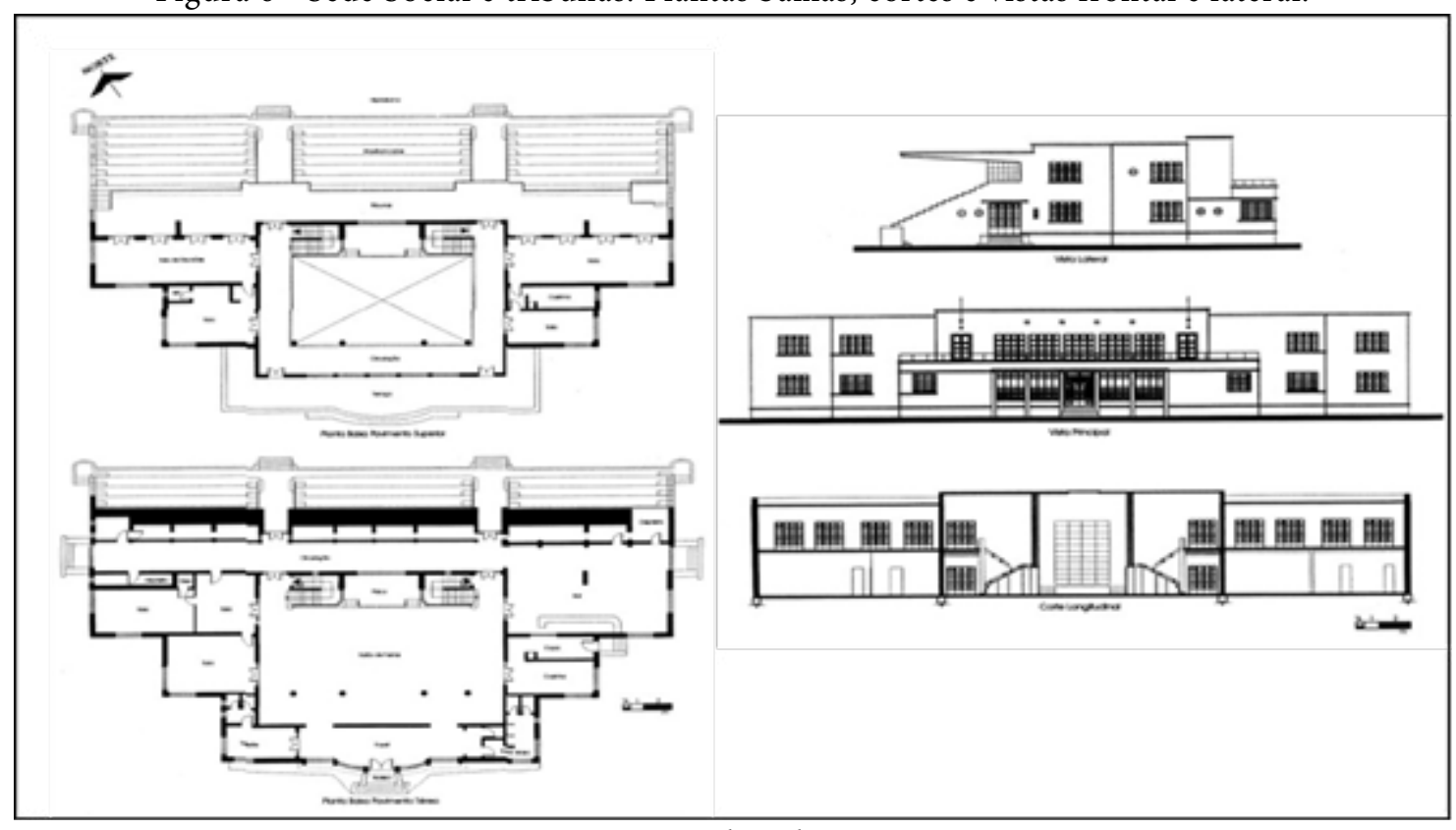

Fonte: Desenhos da autora.

O Salão Nobre, segundo momento, está conectado a partir de um eixo transversal central a funções laterais. De um lado, duas salas de estar com portas amplas - as quais definem uma ampliação eventual, larguras idênticas e comprimentos diferenciados. De outro, funções de apoio e de serviço, sendo que na ala de maior comprimento acomodase um bar, integrado ao salão e exterior, e na menor situam-se copa, cozinha, sanitário de serviço, depósitos, acesso de serviço e carga e descarga.

Em terceiro, o palco, levemente elevado, destaca-se por um painel em vidro de dupla altura, sutilmente limitado pelas escadas laterais de duplo lance, que atingem o segundo pavimento. A partir deste acesso fica configurado um mezanino em U, que avança nestas três laterais sobre o salão através de balcões, na forma de um semi teto no contorno, o qual define sutilmente uma pista de dança que coincide, por sua vez, com o teto maior. 
Repetem-se os compartimentos periféricos do térreo no pavimento superior. $\mathrm{O}$ mezanino interliga-se longitudinalmente com um terraço frontal e plataforma posterior e transversalmente com salas laterais e copa com monta-carga.

Por último, a plataforma que avança em um grande balanço sobre as tribunas, a partir do limite posterior do segundo pavimento do Salão de Festas, define o perfil do prédio, que insere pelo seu desenho a identificação à distância, da função ao qual está destinado.

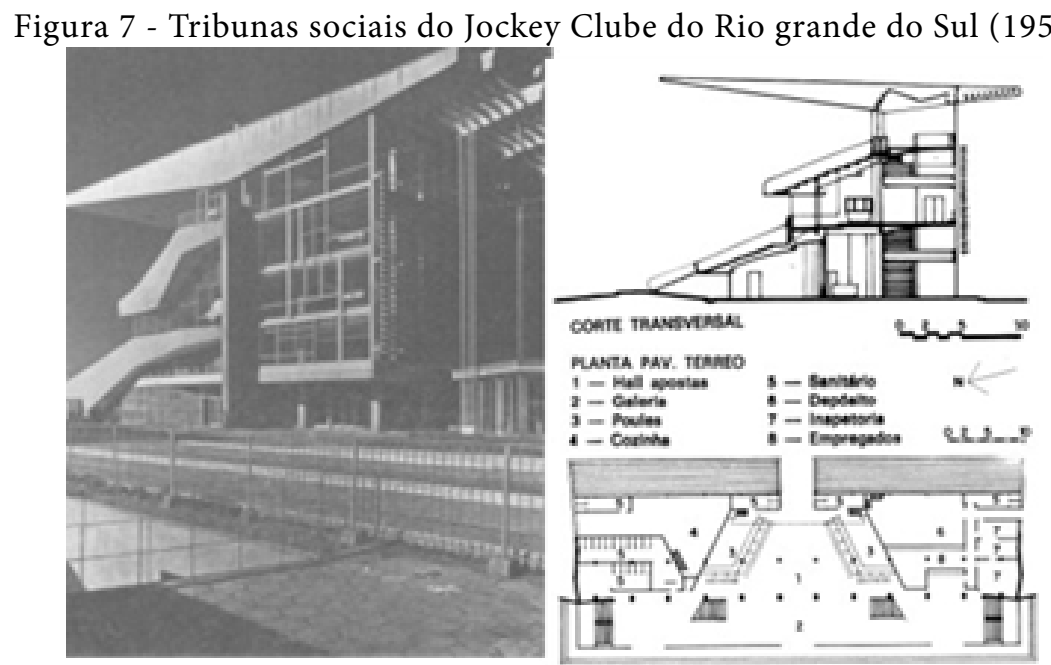

Fonte: XAVIER, Alberto; MIZOGUGUCHI, Ivan (1987).

A hipótese é de uma atitude projetual com fortes vínculos a premissas na formação de um tipo de origem temática, pela combinação destas duas funções nobres em outros exemplares programáticos anteriores, ou seja, Jockey Clube de São Paulo e Rio de Janeiro, bem como, $a$ posteriori, o Jockey Clube de Porto Alegre (Figura 7).

Os quatro momentos descritos, que demonstram a distribuição dos espaços e compartimentos em planta, confirmam-se como uma estratégia de diluição gradual das diferenças dimensionais entre plataforma e a marquise do acesso principal da Sede Social, desenvolvidos mantendo-se a axialidade e a simetria (Figura 8).

Verticalmente verifica-se habilidade na sobreposição das funções e eficiência em uma estratégia que converge para uma das atividades principais do Parque Visconde Ribeiro de Magalhães: o Hipódromo.

Figura 8 - Sede Social e Tribunas da Associação Rural de Bagé.

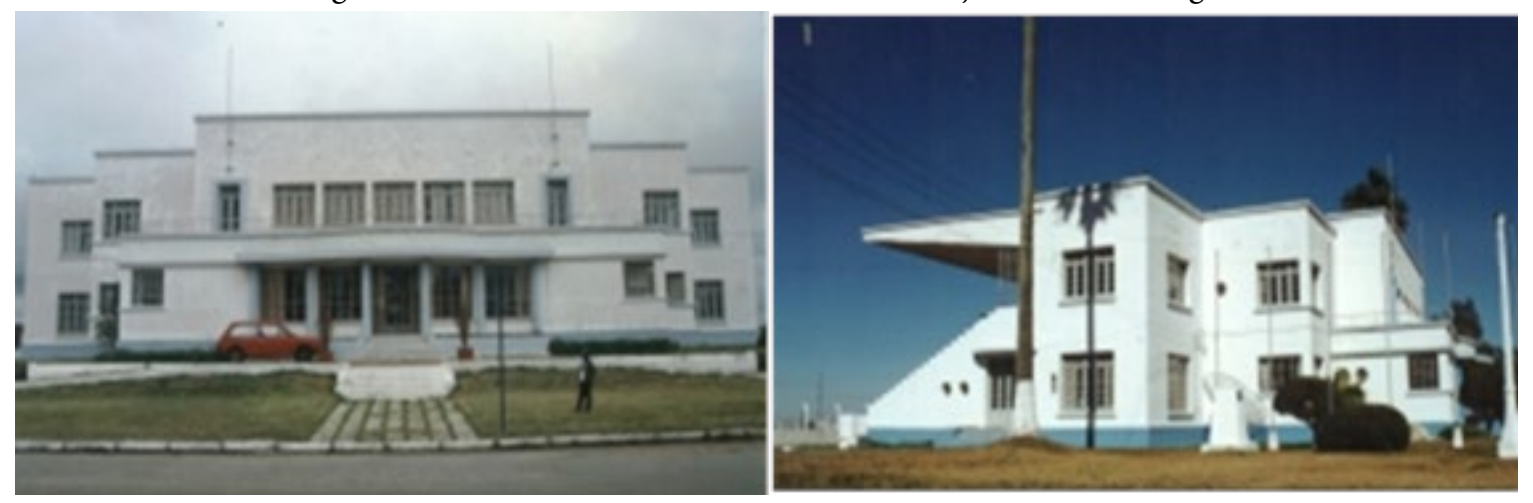

Fonte: Autora. 


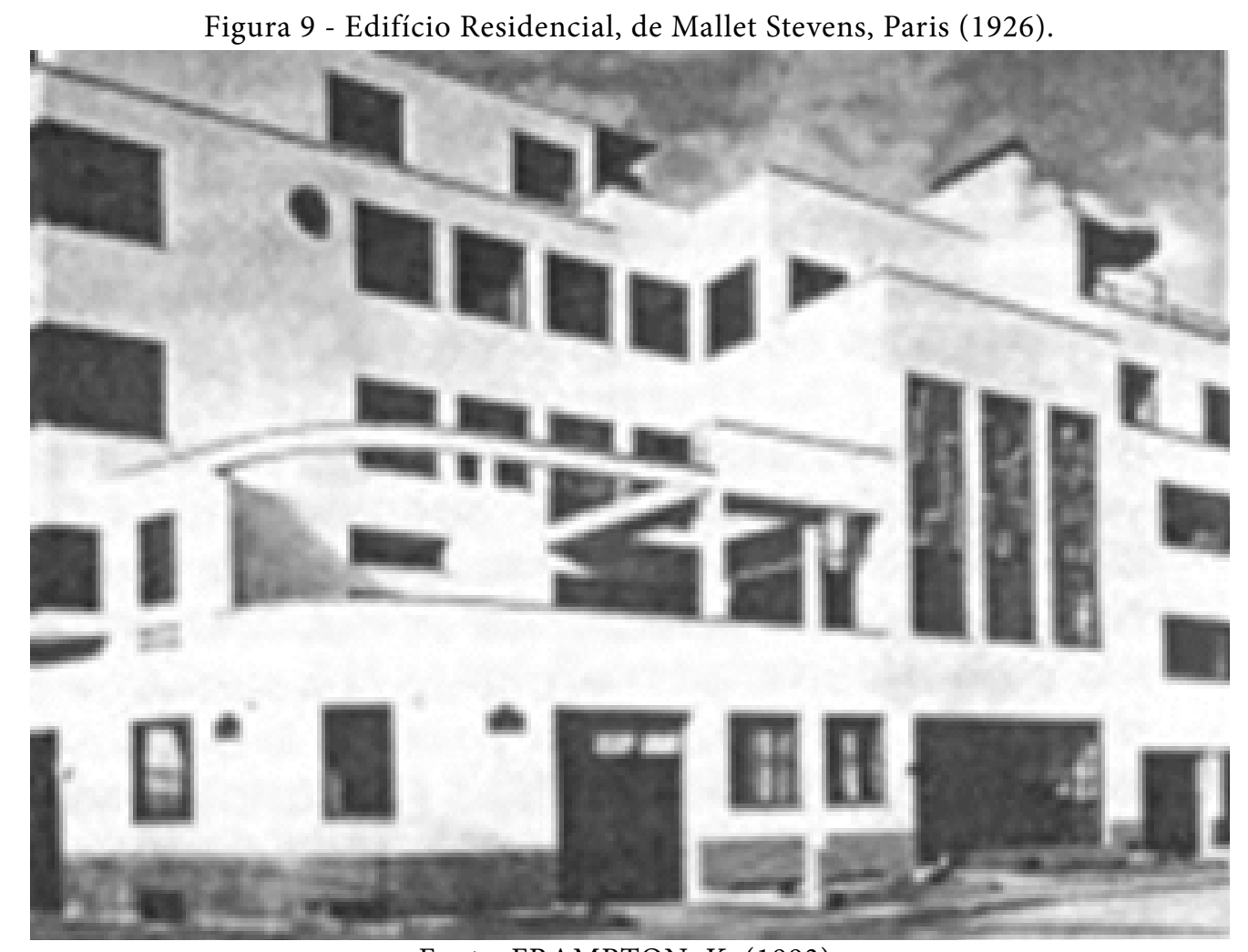

Fonte: FRAMPTON, K. (1993).

Por outro enfoque, observamos neste exemplar uma atitude projetual tradicional, ou seja, uma planta simétrica, com algumas particularidades programáticas. Podese incluir referências estéticas temporais na proposta de Moreira, como do Edifício de Apartamentos do arquiteto Mallet-Stevens, considerado um exemplar pseudo purista, com reforçadas semelhanças com a Sede Social da Rural: arquitetura recortada, esquadrias de canto, esquadrias verticais, terraços levemente curvos, grandes painéis em vidro e ferro, distribuição de cheios e vazios e marcação forte do acesso.

Porém, o evento da Exposição do Centenário da Revolução Farroupilha, implantado no Parque da Redenção, em 1935, em uma cidade como Porto Alegre, que na década de 1930, era subsidiária da política nacionalista de Vargas, evoca ares de modernidade.

Em resposta a esse momento, a arquitetura gaúcha delineia-se, sensivelmente, influenciada pelos pavilhões de uma exposição, ainda que efêmera, canal do maior fenômeno de comunicação de massas já presenciado no Estado. Segundo Davi Eskinazi (1995, p. 5-6), a cidade insere-se naquele momento dentro de uma tendência mundial conservadora, difundida entre guerras, que buscava a fusão da tradição arquitetônica com a estética moderna numa síntese denominada por Kenneth Framplton de Nova Tradição. Já Segawa coloca que:

O caráter efêmero dessas obras conduzia a opções simples de construção e decoração: [...] o despojamento ou arrojo ornamental subordinava-se ao sistema construtivo empregado, e o déco confluía por uma solução formal menos rebuscada. (1997, p. 62). 
Portanto, pode-se afirmar que a influência desencadeada pela provável observação de Carlos Moreira dos pavilhões construídos na exposição, e o ambiente de uma arquitetura protomoderna praticada na capital e no Estado, reflete-se como uma forte marca nos exemplares projetados para a Associação Rural de Bagé.

De um lado: a Exposição Farroupilha, de 1935, com seus pavilhões no art déco, espelhos d'água e outros elementos, a partir de um pórtico e eixo monumental. De outro: o conjunto Pórtico, Sede Social, Tribunas da Associação Rural de Bagé, Bacia (reservatório) e Pavilhões, aliados à via de acesso e vias secundárias, onde anualmente, desde a Sede Antiga, realiza-se a Exposição Feira de Bagé, a qual reúne grande público durante uma semana.

Desta forma, aponta-se influências desprendidas da “Exposição do Centenário da Revolução Farroupilha" para o Parque Visconde Ribeiro de Magalhães, tanto em nível global, macro estrutura, quanto em nível das construções, bem como visível a relação programática com a família de clubes de jockey no Brasil.

\section{Aspectos Conclusivos}

Vislumbra-se em Moreira clareza no seu método projetual, retratada nestes dois exemplares, e a priori destacamos seus elementos de composição da tradição acadêmica, e elementos de arquitetura dentro de uma modernidade contida.

Por outro lado, em uma análise conjunta de sua obra, verifica-se que as roupagens mostram uma diversidade estética, em voga na época (anos 1940), entre os engenheiros e arquitetos, quase sempre vinculada a uma planta tradicional.

A iniciativa da Associação Rural de Bagé, nos anos 1940, a destinar a autoria do conjunto do Parque de Exposições Visconde Ribeiro de Magalhães ao engenheiro Carlos Moreira, permite que contemplemos até os dias de hoje exemplares que retratam a arquitetura de uma época, na estética protomoderna com elementos déco e que se adapta às atividades da associação até os dias de hoje.

Por todos esses fatores mencionados neste estudo, os prédios do Pórtico de Acesso, da Sede Social da Associação Rural e Tribunas incluem-se os dois exemplares no inventário bajeense de bens edificados, junta a outros imóveis de importância arquitetônica, cultural e histórica para a cidade de Bagé (Figura 10). 
Figura 10 - Ficha Associação Rural de Bagé.

INVENTARIO DOS BENS EDIFICADOS DO RIO GRANDE DO SUL

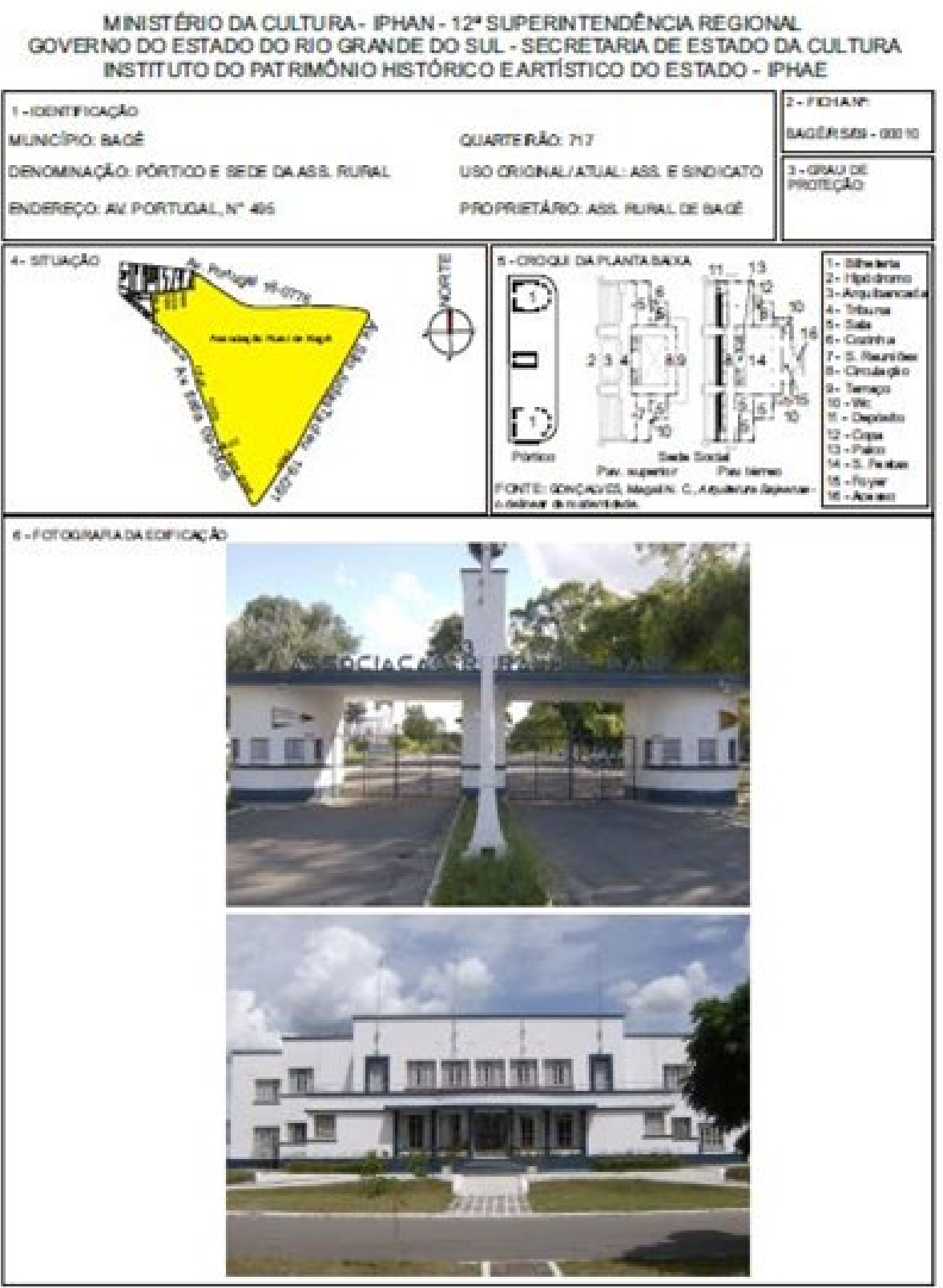

Fonte: Formulário IPHAN/IPHAE (2009).

A análise, ora desenvolvida, reforça a pertinência da preservação do conjunto do Pórtico de Acesso e Sede Social e Tribunas da Associação Rural, mantendo-se na íntegra, com todos seus elementos construídos, externamente e internamente (Figura 11), perpetuando-se definitivamente no quadro da arquitetura bajeense, o que se confirma a partir do "Inventário do Bens Edificados do Rio Grande do Sul - Ministério da Cultura - IPHAN - 12a Superintendência Regional do Rio Grande do Sul - Secretaria de Estado da Cultura" e pelo "Instituto do Patrimônio Histórico e Artístico do Estado - IPHAE”, em aplicação vigente no município, tutelada pelo Conselho Municipal de Patrimônio Histórico de Bagé - Compreb. 
Figura 11 - Ficha Associação Rural de Bagé. Detalhes externos e internos.

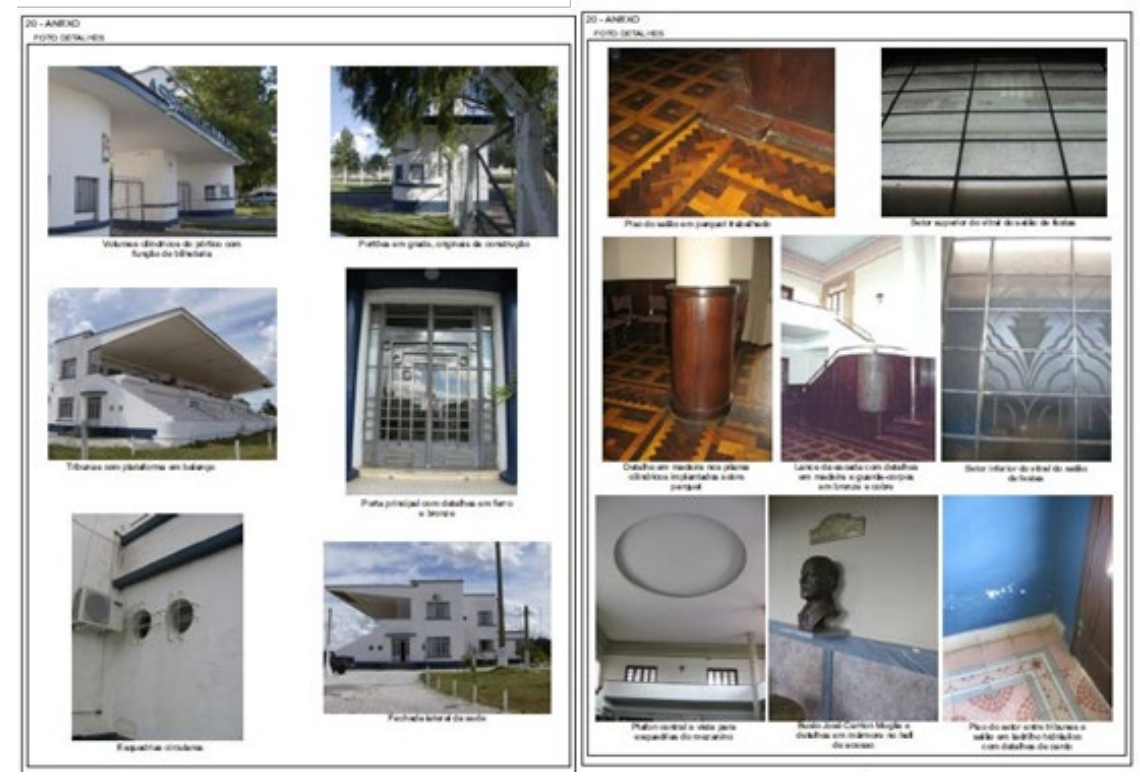

Fonte: IPHAN/IPHAE (2009).

\section{Referências}

BROADBENT, Geoffrey. Diseño Arquitetónico y Ciências Humanas. Barcelona: Gustavo Gili, 1976.

ESKINAZI, Davit. Arquitetura e tipologia na exposição comemorativa do Centenário Farroupilha de 1935. Dissertação (Mestrado em Arquitetura) - Faculdade de Arquitetura, Universidade Federal do Rio Grande do Sul, Porto Alegre, 1995.

FRAMPTON, Kenneth. Historia critica de la arquitectura moderna. Barcelona: Gustavo Gili, 1993.

GONÇALVES, Magali N. C. Arquitetura Bajeense - o delinear da modernidade: 1930-1970. Dissertação (Mestrado em Arquitetura) - Faculdade de Arquitetura, Universidade Federal do Rio Grande do Sul, 2006.

MAHFUZ, Edson da Cunha. Ensaio sobre a Razão Compositiva. Belo Horizonte: AP Cultural, 1995.

SEGAWA, Hugo. Arquiteturas no Brasil: 1900-1990. São Paulo: EDUSP, 1997.

XAVIER,Alberto; MIZOGUCHI, Ivan. Arquitetura moderna em Porto Alegre. São Paulo: Pini, 1987. 